\title{
JAKUB NOWAK
}

Political Science Faculty Maria Curie-Sklodowska University, Lublin, Poland

\section{On the Concept of Figurations, Deep Mediatization, and the Adulthood of Media and Communication Studies - the Interview with Andreas Hepp}

Andreas Hepp is Professor of Communication and Media Studies at the Centre for Media, Communication and Information Research (ZeMKI), University of Bremen. Mediatization research is among his various research interests that generally include media and communication theory, media sociology, and transcultural communication. Theoretical and empirical studies on mediatization processes are also among the leading subjects in the academic work of ZeMKI.

Andreas Hepp is the author of several publications on the subject of mediatization, including his latest book The Mediated Construction of Reality co-authored with Nick Couldry of the Department of Media and Communications, London School of Economics and Political Science. In The Mediated Construction of Reality, Couldry and Hepp revisit the question of how the social world is constructed, originally posed by Peter Berger and Thomas Luckmann (1966), and provide the reader with their own original answer, acknowledging the complex and irreducible contribution of digital media to the process. The editorial staff of Mediatization Studies reckons Hepp as one of the leading academics in the field of mediatization research and The Mediated Construction of Reality as one of the most interesting and up-to-date accounts on the issue. This is why we decided to present it via this interview.

The interview was conducted during the Communicative Figurations international conference in Bremen (December 7-9, 2016), which focused on transforming communications in times of deep mediatization. Couldry and Hepp's book had its official presentation during the conference. 
Jakub NowaK: Mediatization is not about media effects.

ANDREAS HePp: No (laughs). Of course, there are different understandings of mediatization around, but as Nick Couldry and I wrote in our book (Couldry, Hepp 2016), what we really understand under this term - and that's a kind of basic understanding of mediatization - is that it tries to grasp how the change of media and communication relates to the change of culture and society. The term reflects certain kinds of interrelations and interdependencies but, in contrast to mediation which only focuses on processes of mediated communication at a certain moment of time, the concept of mediatization is being used to describe long-term transformations in relation to media and communication. I would say this is a basic understanding of the term that most scholars could agree on.

There are different ways in how this interrelation can be theoretically and empirically best grasped. You can find different orientations and traditions within media and communication research. Some of them are institutionalist traditions, others are social-constructivist. There is a discussion as to whether there is even a third tradition, called materialist tradition, and so on.

JN: The way you perceive social and cultural change - as expressed in your book - underlines the significance of human agency in the process. You borrow it from Norbert Elias.

AH: Yes, this is Elias' way of thinking; but also Peter Berger and Thomas Luckmann's social constructivism in general. So, the core argument here, I would say, is that you only have media-related changes as long as, on the one hand, the practices of people change in some fundamental way, but also, on the other hand, when structured relations between these people change, as well as their orientation to practice.

Following the Elias tradition, we use the term "figurations" to describe these processes. Elias' thinking would be: when you have a durable transformation of culture and society, figurations of culture and society transform. And this can take several generations; but sometimes you witness eruptive changes. We call them "waves". The point we made in the historical chapter of the book is that we have to develop this complex and non-linear thinking about "process" if we want to better understand mediatization. There are particular waves of mediatization but you can also observe smaller shifts in culture and society in relation to media and communication. The main challenge for each kind of mediatization research is that these changes within the media environment have manifold consequences depending on the social domains - or figurations - under consideration.

For example, the emergence of so-called social media means something different if you have several kinds of organizations in mind, like schools or political parties, or if you consider collectivities like families or youth groups, and so on. And datafi- 
cation is the last move in this process. This is the reason why we tried to develop this comparatively complex approach of grasping what we call "deep mediatization", by which we understand the latest stage of mediatization.

JN: It helps you avoid simple causalities as mediatization is about various figurations overlapping.

AH: Exactly.

JN: When describing relations between human agency and the media, you use the concept of molding forces of the media. Could you explain this?

AH: Actually, when I look at my old writing, I think it is my most misunderstood argument.

JN: What is so tricky about it?

AH: It is not tricky. When you look in detail into that chapter in Cultures of Mediatization [Hepp 2012a, pp. 29-68] or the article that was the basis for it [Hepp 2012b], you will see I reflected on the words molding and shaping which are used by many scholars to describe a certain kind of media influence. However, my argument was that these words are just a metaphor for media influence and we should move behind this metaphor. If you look there in detail you end up with social processes, especially institutionalization and materialization - or reification, or naturalization - of communication in relation to the media.

What I tried to figure out in that chapter - and this is my core argument there - is that we should use more sophisticated concepts of social sciences instead of using metaphors like "shaping", "molding", or whatever. But that chapter is very often quoted in the sense I would try to push this metaphor of "molding", which from my point of view was never the goal.

JN: Especially in the context of how you understand the concept of figurations.

AH: If you do mediatization research, the basic challenge is that you need some kind of concept on the basis of which you can analyze the mediatization of various different social domains. You have to operate on a kind of meso level: that is, "between" the individual and an abstract such as "the whole society". So, it makes no sense to formulate overall generalizations on the mediatization of society such as you can find, for example, in the medium theory. It is just too abstract to say: "we moved from the print culture to the television culture, and then to the digital culture". This way of thinking is too general and it is valid only on a metaphorical level. 
$\mathrm{JN}$ : A kind of narrative.

AH: On that level: yes. However, it also falls short on the individual level, when you try to consider how certain media have affordances on the individual. If you follow this argument, the idea is to move on to the meso level, for example, of collectivities, or organizations. And this is where media-related changes come into life. Taking this as a starting point, the main question is how can you research the transformation of such very different things in a comparative way and how does this relate to the changing orders of society.

A good starting point for that - for Nick and me - is the concept of figurations Elias has offered. Following his way of thinking, a family is a figuration. But also many other kinds of organizations.

JN: Like this conference.

AH: Yes, exactly. So, a figuration is an interdependency of people who have a shared orientation in practice, frames of relevance - as they are oriented to family life or a certain kind of organization, and that is based on particular practices by which this figuration is brought up in an ongoing process. And of course, this actor constellation within a figuration has certain kinds of power relations. Elias called them "power balances" - and "balance" here does not mean equality. Rather, it means people having particular power positions in certain figurations. Giselinde Kuipers [2017] recently made the very important argument that we should move more into this direction when analyzing figurations. When it comes to power, figuration is a specific analytical tool that helps you empirically describe the media-related changes of very different social domains. All of these led us to that figurational perspective, which is, on the one hand, certainly radical in its process thinking; but on the other hand, it is very practical as you can use it in your empirical research.

JN: The first versions of your concept of communicative figurations consist of "media ensembles" as one of figurations' characteristics. Later you decided to change it for "forms of communication". Does this correction go beyond just switching terms?

AH: If you look back at our early writings, the argument was to think about figurations on four levels, which were: actor constellation, thematic framing, practices of communication, and media ensemble.

JN: Later you combined the last two into one.

AH: Yes. When we developed the concept further, we decided to underline that practices of communication are nowadays deeply entangled with the media ensemble. It 
just does not make sense to separate practices from the media: this is since it is only because of the media which are used that certain practices of communication are fully developed and can be understood as such. We merged this into an extended practice point of view. Therefore, it is about moving practices to the foreground, but also about reflecting practice in relation to certain kinds of media.

It is not only Nick and I but also other colleagues who have been developing this idea for about six or seven years now. If you look back, you see this is a certain kind of development. For us, many steps of this development are based on our own empirical research. We realized we must re-theorize certain things to make the concepts work properly. The first article on the issue that I wrote with Uwe Hasebrink is far less focused on questions of deep mediatization [Hepp and Hasebrink 2014] than our present work. These reflections were much more related to older forms of mediatization. Looking back, I think it is also much less analytically open, as it still has a kind of naïve functional thinking inside. In the further development, we tried to move this out.

JN: If the concept is more focused now on the process of deep mediatization, to what extent can it also be used in historic research?

AH: I do think it is highly helpful in historical research. The figurational thinking offers an analytical tool to compare really fundamental processes of how social reality is constructed in various contexts as well as across various periods of time. In addition, it is a critical concept as it focuses on power relations and also on the question of how certain figurations can produce various conflicts, exclusions, and so on. On a basic level, it just means looking at particular things: the orientation that people have in practice, the actors' constellation they build, the practices of people communicative practices if you have a meaning dimension in the foreground - and their entanglement with media. All of these build into a certain kind of connection, a meaningful connection, and this smallest "unit" on the basis of which society is built up. Nick and I tried to develop this idea further in the book also by reflecting on how certain kinds of figurations build up more complex kinds of figurations, that is more complex forms of society.

If you look back, my first publications on the concept were a chapter in my book Cultures of Mediatization [Hepp 2012a] and an article [Hepp 2013] I published around the same time. Nick also partly used this concept of figurations in his book Media, Society, World [Couldry 2012]. On such a basis, we tried to develop it further over the past few years. For us, the concept gives answers to an important research challenge: nowadays, you can no longer reflect on the influence of media by taking a single media point of view. It is not just the affordance of one medium that makes the difference but the variety of different media coming together in certain kinds of figurations. Think about a family: it is not just television, it is not just a mobile phone, it is all these things 
coming together that makes the difference. Taking this as a starting point, you find yourself in need of another analytical concept in media and communication research other than the medium as such.

JN: The core of the book is the diagnosis of deep mediatization. What is the difference brought about by the process when compared, to use your term, previous waves of mediatization?

AH: To use the term "deep" means to put emphasis on various parts of today's society that could not exist in this form without media. Think about, for example, the figuration of the financial market: in its present form it depends fundamentally on certain kinds of media and their infrastructures. Without them it just could not exist. And - if you look back historically - this deep relatedness to media and their infrastructures becomes more and more radicalized. Another important point about deep mediatization is that the latest wave of digitalization makes it possible to delegate certain forms of agency to algorithms. Particular moments of social construction are now delegated to certain kinds of technological media-related procedures.

We decided to develop a new term for these processes because we felt uncomfortable about just saying that mediatization is always the same. We were also not convinced by how various scholars develop certain kinds of step-models of mediatization. These models, from our point of view, are usually too simplistic and not radical enough: they do not reflect on the latest step of mediatization we are presently confronted with.

At the beginning, we thought about calling it "radical mediatization" but we dropped the term as it can have political implications which are important to keep for an analysis of other, political phenomena. Finally, we ended up with "deep mediatization".

JN: Following up on delegating people's agency to computers: Wendy Chun [2004] writes that software works as functional equivalent to ideology, as it sets limits of human action in a discreet way. Do we have to redefine the concept of agency if, nowadays, more and more often we do not know the exact rules of how all those online environments work?

AH: Yes, for most people computers are black boxes. But I would hesitate to say that we need a different definition of agency. First of all, I think the core point of the concept is that it is about human agency. And I really think that we can relate here - in a certain way - to an understanding of agency as we know it from the practice theory. What happens, when it comes to algorithms, is rather a process of delegation: we delegate certain processes of social construction to software because we as human beings have the agency for this. Then it seems that these algorithms do the things on their own. For many people this leads to some kind of naturalization and, by that, reification of particular media technologies. This delegation makes people think: "it is natural 
that it works this or that way", and it means people forget that it was human agency that was the starting point. Thinking about this, Nick and I would really make a clear cut to compare our idea to Bruno Latour's Action-Network Theory, which theorizes also the agency of machines and things in general. From our point of view, this is problematic as it mixes human agency - which is always meaningful - with precisely this process of delegating it, which is something empirically different.

What we rather need to rethink is how to find appropriate concepts for describing this process of delegation. It would be a big mistake to broaden the concept of agency to everything, as it is done partly in academia. Doing so, we lose the critical standpoint.

JN: To look at the issue from a different point of view. Considering software as political resource raises the problem not only of interrelations between people and data but also between people and depositaries of data; that is, Internet companies. Nowadays, they not only shape the limits and conditions of how we socialize or participate in culture in online environments but also monetize all our activities online.

AH: I think there are various levels of complexity there. Referring to your question, it is a help to make some kind of experiment of imagination. Think back to the times we call the Seventies: as we were living back then, if something like the Internet had come up, it would have been obvious to think of it as something "public", a kind of "public service". Back in those days, at least in Europe, there was a dominant understanding that all important kinds of infrastructures should be public - they are too important not to be controlled independently vis-à-vis commercial interest. But the Internet came up after a phase of so-called deregulation and its extension was in parallel to the increasing processes of commercialization.

And yes, it is nowadays at various levels "owned" by companies and that fact also brings various levels of complexity. I would say the first and principle level of complexity here is a question of fundamental democratic control. Various processes occurring in "the Internet" are under the control of private companies and there is no public insight in the process. And paradoxically, when you have state engagement in the field several kinds of agencies and surveillance become involved. It is not just "the public"; there are also state interests. In a certain way, this is the complexity that we have to think about.

And, again, taking a figurational perspective on that can be quite useful. It helps you think about various influences of certain kinds of companies but also states on building up specific figurations which you understand as important for present societies.

JN: What about data we can collect from the Web as resource for our research? There are claims we do not need social theory anymore since we are given precise information on whole populations. 
AH: I think this is just rubbish. First of all, this is a methodological or even epistemological question. Only if you have a firm theoretical standpoint, can you make sense of data. Even of what is called "Big Data".

JN: To be able to comprehend it?

$\mathrm{AH}$ : Well, the point is that very often it is a certain kind of implicit theory which is behind that. If you look back into that article by Chris Anderson [2008] that you probably have in mind when raising this argument about social theory and data, the theoretical mistake Anderson makes is that he fails to acknowledge that the very concepts he uses are based on implicit theories. Already to say that the social is built up out of individuals, which is behind many procedures of big data collection, is an implicit social theory. The figurational perspective would say it is not just about the individual but about the individual acting within particular figurations. So this argument falls short theoretically. There is no possible understanding of the world beyond theoretical standpoint.

JN: Going back to your and Nick Couldry's book: why did you write it now? And why a book about deep mediatization?

AH: Well, we started developing our idea for the book shortly after we finished our previous books: Nick had written Media, Society, World and I had just finished Cultures of Mediatization. Both of them came out more or less at the same time and we found these books were related in a certain way. Nick had included some sections referring to mediatization in his book - but it was not its core. On the other hand, in my book there was this relation to practice theory that Nick had developed in his work. We had in mind that the anniversary of Berger and Luckmann's book was coming up and we both agreed for very long time that we have to fundamentally rethink the process of social construction when it comes to the present stage of mediatization. For us, this was the starting point to think about writing The Mediated Construction of Reality. Then we talked with John B. Thompson and Andrea Drugan from Polity Press about the idea and they were very positive about it.

Writing this book was of course a challenge, because we took a classic publication as a point of departure. But from the beginning our idea was not to write a book that would be a reflection or criticism of that of Berger and Luckmann. We had the idea to write a different book. We wanted to take their fundamental question - the one about the construction of reality - and elaborate our answer to it nowadays. I think our book reflects the same topics, the same problems that Berger and Luckman called subjective and objective dimensions of society when it comes to socialization, for example. But the structure of the book we wrote is completely different. I would even say you can perceive our work and how we structured the book as an expression that 
we live in completely different times. You cannot write a book nowadays with the same structure that Berger and Luckmann had.

And in addition: there is also an academic friendship between Nick and me in the story behind this project. When writing a book so strongly based on theory you must share the fundamentals of thinking, it is impossible otherwise. We really had that feeling that such a book was necessary. It was necessary for us to clarify our thinking. But we also thought it might be helpful for others.

JN: Do you think that, nowadays, we are facing a unique moment for media and communication studies when scholars look back to sociology more than they did two or three decades ago?

AH: I would put it this way: media and communication as a field or as a discipline, however you want to call it, is reaching adulthood. This means that it is not enough today simply to say "it is a two-step flow of communication" or to discuss questions of "agenda setting", or whatever often highly specific theory developed within the field. I think it is quite obvious that we are not able to explain what is going on with relation to media just with these classic theories anymore.

So, what is required - also from other disciplines - is to develop broader ideas and concepts. Of course, they should speak to the classical theories to integrate the knowledge being produced on this basis. But I think the current tendency in the field is that there are various scholars trying to develop a broader understanding of what is going on with the world today when it comes to media, digitalization, and datafication. I would say that the book by Nick and myself is part of a more general...

JN: ...wave?

AH: ...Wave, or figuration of people who have the feeling that media and communication as a field also has to give something back in a sense of a proper social theory.

\section{Bibliography}

Anderson, C. (2008, June 23). The End of Theory: The Data Deluge Makes the Scientific Method Obsolete, Wired, https://www.wired.com/2008/06/pb-theory/ [access: 30.01.2017].

Berger, P., Luckmann, T. (1966). The Social Construction of Reality. A Treatise in the Sociology of Knowledge, New York: Anchor Books.

Chun, W. (2004). On Software or the Persistence of Visual Knowledge, Grey Room, vol. 18, pp. 26-51.

Couldry, N. (2012). Media, Society, World: Social Theory and Digital Media Practice, Cambridge: Polity Press.

Couldry, N., Hepp, A. (2016). The Mediated Construction of Reality, Cambridge: Polity Press. 
Pobrane z czasopisma Mediatizations Studies http://mediatization.umes.pl

Data: 26/04/2023 11:44:18

Hepp, A. (2012a). Cultures of Mediatization, Cambridge: Polity Press.

Hepp, A. (2012b). Mediatization and the 'Molding Force' of the Media, Communications, vol. 37, no. 1, pp. 1-28.

Hepp, A. (2013). The Communicative Figurations of Mediatized Worlds: Mediatization Research in Times of the 'Mediation of Everything', European Journal of Communication, vol. 28, no. 6, pp. 615-629.

Hepp, A., Hasebrink, U. (2014). Human Interaction and Communicative Figurations: The Transformation of Mediatized Cultures and Societies, [in:] K. Lundby (ed.), Mediatization of Communication, Berlin, New York: De Gruyter Mouton, pp. 249-272.

Kuipers, G. (2017). Communicative Figurations: Towards a New Paradigm for the Media Age?, [in:] A. Hepp, B. Breiter, U. Hasebrink, (eds.), Communicative Figurations: Transforming Communications in Times of Deep Mediatization, London: Palgrave Macmillan, in press. 